\title{
The own method and program of isotope quantitatively assessment of perfusion in muscles of upper limbs (initial report)
}

Dariusz Niewiadomski ${ }^{1}$, Wieslaw Tryniszewski ${ }^{1}$, Wojciech Marzec², Marian Brocki², Jacek Mikosiński², Iwona Raciborska1, Zbigniew Maziarz ${ }^{1}$

'Department of Radiological and Isotopic Diagnostics and Therapy, Medical University of Lodz 2Department of Chest Surgery, General and Oncological Surgery, Medical University of Lodz

[Received 9 XII 2013; Accepted 7 I 2014]

\begin{abstract}
BACKGROUND: The issue of blood flow in muscles has been dealt with for many years. However, most often it was assessed qualitatively with standard vascular examinations. The quantitatively perfusion assessment is indispensable in the normal and pathological conditions. Some diseases impair the perfusion mainly in the area of upper limbs. It can be observed in Raynaud's disease, vascular occlusive diseases, neurological disturbances, and thermal injuries. Hyperhidrosis of upper limbs after sympathectomy of thoracic part of sympathetic trunk may bring closer the diagnosis statement. Nuclear medicine has the markers and methods that allow for the assessment of the volume of perfusion in muscles. The aim for creating this method and program was the development of radioisotope method allowing for quantitative assessment of perfusion in muscles of upper limbs. This should lead to calculating the perfusion index and its range of normal values in a greater group of patients and to using this method both in the healthy and pathological conditions.

MATERIAL AND METHODS: 20 patients, age $30.4 \pm 7.1$ years, who underwent following examinations: qualification to the group, medical history, subject examinations, USG of upper limb vessels, anthropometric examinations, biochemical and hormonal blood tests, the assessment of upper limbs with USG Doppler and FMD (flow mediated dilatation), radioisotope examinations with gamma camera BrightView XCT by own program RAPUL (Radioisotope Assessment Perfusion of Upper

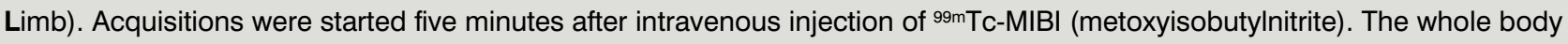
scintigram and scintigrams of arm and forearm muscles in A-P projections were taken.

RESULTS: In the examined patients, the results of anthropometric, biochemical and hormonal test were within the range of normal values. In radioisotope quantitative assessment of perfusion, perfusion indexes of left arm were $20<\mathrm{PI}_{- \text {left }}<11.90$ and of the right arm $7.00<\mathrm{Pl}_{\text {-right }}<12.30$. The dependency correlation $\mathrm{PI}_{\text {-left }} \mathrm{vs}$. $\mathrm{PI}_{\text {-right }}$ was strong $\mathrm{r}=0.92036$.

The values of perfusion symmetry index (IPS) had a normal distribution and were within the following range: $0.9231<$ IPS < 1.1019.

CONCLUSIONS: The RAPUL method and program allow for quantitative assessment of perfusion in muscles of upper limbs. Developed program has a high repeatability of results. The results in the bigger group will allow for defining the range of normal values of perfusion index in muscles of upper limbs at rest. These will be diagnostically used both in healthy (sports medicine, military services) and pathological conditions.
\end{abstract}

KEY words: muscle perfusion, normal values, perfusion indicator, scintigraphy, upper limbs

Nuclear Med Rev 2014; 17, 1: 13-17

Correspondence to: prof. dr hab. n. med. Zbigniew Maziarz

Żeromskiego 113, 90-549 Łódź, Poland

Phone: +48426393686

Mobile: +48603 882309

E-mail: zbigniew.maziarz@umed.lodz.pl

\section{Background}

The impairment of microcirculation is a clinically known process. However, our knowledge concerning the beginning of this process is insufficient and the early information about these changes can influence the time and methods of treatment and give better therapeutic results. Microcirculation has a crucial role in muscle perfusion, thus its quantitative study is necessary for 
the assessment of quantitative values at rest and at stress, as well as in medical and normal conditions. The impairment of perfusion in muscles in the initial stage of the disease is symptomless and difficult to recognize both for the patient and the doctor [1, 2]. However, the lack of clinical symptoms doesn't mean that there are no perfusion disturbances in circulatory system. The issue of blood flow in muscles has been dealt with for many years. However, the assessment was usually focused on the circulatory system functions mainly in big vessels. The impairment of muscle perfusion was most often assessed with standard vascular examinations. None of these methods assessed the perfusion quantitatively and none of them gave the comparison between muscle perfusion at rest and stress. Hitherto techniques usually involved qualitative assessment of perfusion changes in consecutive examinations. Most of them, due to their complexity, were used mainly in scientific researches. The size of muscles perfusion of upper and lower limbs, as a physiological process, should have quantitative parameters that would define its normal values range. Nuclear medicine has markers and methods that allow for the assessment of muscle perfusion size with radiopharmaceutical ${ }^{99 m} \mathrm{TC}-\mathrm{MIBI}$ which accumulation in muscles is proportional to their perfusion [3-7]. The sensitivity and specificity of the examination with ${ }^{99 m} \mathrm{TC}-\mathrm{MIBI}$ is assessed for $81 \%$ and $90 \%$ in the detection of disturbances of the perfusion in the muscles of lower limbs [8-10]. For many years, in the Institute of Nuclear Medicine of University Clinical Hospital, Lodz, we have been conducted, with our own quantitative method and program, the researches assessing the perfusion in the muscles of lower limbs at rest and stress. The obtained results allowed for defining the range of normal values of lower limb muscle perfusion. Our researches have been published many times $[11,12]$. All scientific and clinical studies that deal with the issues of muscle perfusion are worth attention [13-23]. There are still trials to find safe and highly sensitive diagnostic tests that would assess muscle perfusion quantitatively not only in the area of lower limbs. Some of the diseases impair microcirculation not only in the lower limbs but sometimes they have the influence only on the perfusion of the muscles in upper limbs. Vascular diseases of the upper limbs are still an underestimated problem among the doctors, despite the fact that they lower the life quality of many patients. These disturbances may be present in many diseases and the early recognition and detection of improper muscle perfusion may play an important role in monitoring the course of disease and efficiency of treatment methods. The symptoms of Raynaud's disease usually accompany the connective tissue diseases, vascular occlusive diseases, neurological disturbances, thermal, electrical injuries and blood diseases. Quantitative assessment of microcirculation in the muscles of upper limbs in these conditions may help in proper diagnosis. It is also possible to monitor the efficiency of treatment and possible qualification to surgical procedure.

Hyperhidrosis of limbs influences patients' everyday activities and life quality and is connected with psychical burden. This problem goes far beyond cosmetic defect, especially when it concerns the area of upper limbs. During the recent years, sympathetic denervation in the area of thoracic part of sympathetic trunk has been used apart from pharmacological treatment. In this procedure it is necessary to assess the influence of surgical treatment on upper limb muscle perfusion. The examinations may be the basis for defining the possible perfusion complications or their lack after sympathectomy. The above reports create the necessity to search for methods that would, in simple and noninvasive way, define the normal range of perfusion in muscles of upper limbs and allow for stating the deviations from the normal conditions. The basis of creating our method and program, being the aim of our study, was the development of radioisotope method allowing for quantitative assessment of perfusion in muscles of upper limbs and defining the index of perfusion symmetry at rest. The target was to develop a quantitative not qualitative perfusion assessment in muscles of upper limbs and calculation of perfusion indexes and of the range of their normal values in a bigger group. The final purpose is to include the developed radioisotope method to clinical diagnostics with the possibility of its application both in the healthy and medical conditions.

\section{Material and methods}

Hitherto material of the analyzed group included 20 patients 8 women and 12 men, age $30.4 \pm 7.1$ years. The following methods were used in this group:

\section{Qualifying examinations}

Medical history and phisical examiantion for the assessment of patients' condition and USG elimination of circulation disturbances with a special focus on upper limbs' circulatory system. — anthropometric examinations:

— age (years), weight [kg], height [cm], BMl [kg/m²], systolic and diastolic blood pressure [mm/Hg], pulse;

- general, biochemical and hormonal blood tests: morphology, ionogram, glucose, lipid profile, thyroid hormones (FT4, $\mathrm{TSH})$.

All the patients underwent specialist morphological assessment of the vessels of upper limbs with Doppler USG, Color Doppler and Pulse Doppler. USG examinations were performed with PROSUND ALOKA ALPHA 7128 XP/10 and $8 \mathrm{MHz}$ linear head. The measurement was taken in subclavian, arm, brachial and radial arteries.

- the next stage was FMD (flow mediated dilatation) examination,

- development of patients' data base for collecting the results, patient information sheet and informed consent form,

— the final selection to the study group - positive assessment of qualifying examinations,

- medical history, subject examinations, analysis of medical documentation, normal results of blood tests, USG examinations of upper limbs. The patients with detached results were eliminated from the group.

II. Examinations after the application of radiopharmaceutical 99mTC-MIBI

Radioisotope examinations were performed with gamma camera BrightView XCT. Analyzing the activity of given radiopharmaceutical accumulated in the muscles of upper limbs in relation to the whole given dose, we assessed the perfusion displaying microcirculation in upper limbs. The areas of interest $(\mathrm{ROI})$ were generated in the defined localizations and we analyzed the distribution of activity. Acquisitions were taken five minutes after the intravenous injection of radiopharmaceutical 99mTc-MIBI with the activity of $11.1 \mathrm{Mbq} / \mathrm{kg}$ of body mass into the lower limb to avoid the picture falsification at the injection 
site in case of upper limb injection. Standard acquisitions with the whole-body technique in P-A projection were performed with the table speed of $20 \mathrm{~cm} / \mathrm{min}$ with $512 \times 1024$ matrix. The patient was placed with his/her head towards gantry camera. After the whole body scintigram, the patient spread arms at right angle. For the patient's comfort and for avoiding the perfusion disturbances, the arms were supported. Gamma camera's heads placed in one surface at the same time registered the scintigrams of arm and forearm muscles in A-P projection. Acquisitions were taken in matrix $256 \times 256$ for 500 second with the possibility of finishing in case of matrix overfilling. After the examination the registered images were send to workstation EBW. On the basis of the obtained images we calculated the muscle perfusion index (PI) and perfusion symmetry index (IPS) with our own program RAPUL (Radioisotope Assessment Perfusion of Upper Limb).

\section{Statistical analysis}

The obtained results were statistically analyzed with STATISTICA $11 \mathrm{PL}$ software. The normal distribution hypothesis was verified with Shapiro-Wilk test. For the measurable variables we calculated mean value, median, the highest and lowest value and standard deviation. The detached values were eliminated in pairs.

\section{The own program RAPUL}

We developed our own RAPUL program for calculating the perfusion and perfusion symmetry indexes. This program was used for analyzing the performed examinations. First, the whole body scintigram was analyzed. ROI describing the whole body is generated with isobox technique. The operator chooses the area of interest by generating the square $\mathrm{ROI}$ inside which the whole body is described with isocontour ROI. There is a possibility of background isolation to one pixel. At the same time we can measure the length of brachial bone. Another stage is the analysis of arms' scintigrams. First, the size and localization of the area of interest is designated. For this, from the elbow we generate vector 0.8 of the brachial bone length towards the glenohumeral joint and of 0.5 length of brachial bone towards the hand. The ends of vectors designate parameters and position of square $\mathrm{ROI}$ with the size of 1.3 of the brachial bone length. Inside the drawn square we generate $\mathrm{ROI}$ describing the muscles of right arm with isocontour technique. Analogically to the analysis of the whole body scintigram, there is a possibility of background isolation to one pixel. By setting the level of the background isolation for the right arm, automatically the same level is transferred to the scintigram of the left arm. The obtained ROls of the whole body and right and left arm are analyzed in relation to number of calculations per one matrix pixel. On the basis of obtained date we calculated the perfusion index for right/left arm from the formula:

$$
P I_{L / R}=\frac{E C_{W-B}}{E C_{L / R}}
$$

where:

$\mathrm{PI}_{L / R}$ - perfusion index of left/right arm

$\mathrm{EC}_{\mathrm{W}-\mathrm{B}}$ - number of calculations per one matrix pixel of the whole body scintigram

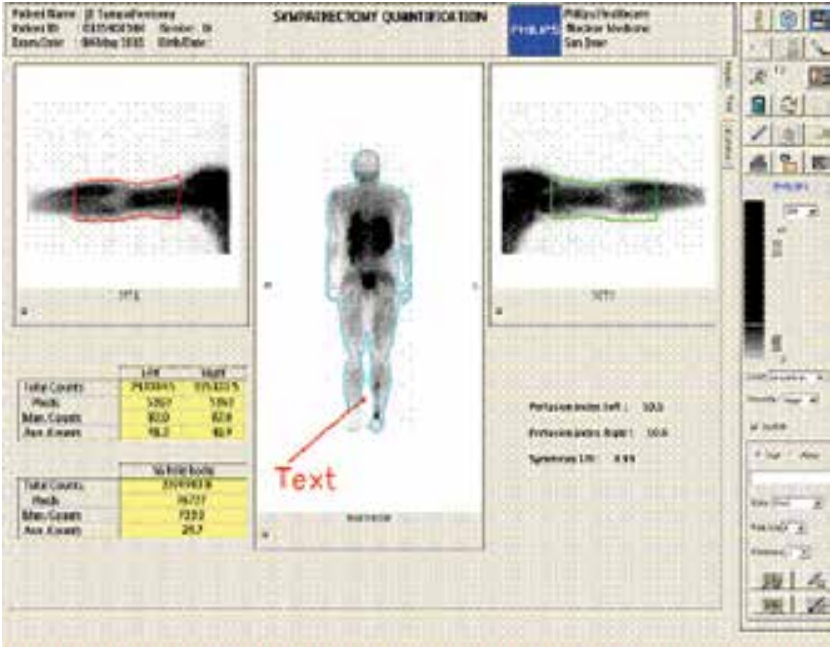

Figure 1. The report with the calculated values of perfusion and symmetry indexes

$\mathrm{EC}_{L / R}$ - number of calculations per one matrix pixel in the right/left arm scintigrams

The perfusion indexes of upper limbs allowed for calculation of the index of perfusion symmetry from:

$$
P I S=\frac{P I_{L}}{P I_{R}}
$$

The symmetry index is defined as the relation of the values of perfusion in the muscles of left and right hand. The results of the examinations are recorded in the report which example is shown in Figure 1.

The developed program was tested on phantoms. The positive results of these tests allowed for the assessments of the method's repeatability via several acquisitions of the same patient. After one examination a patient stood up and the heads went back to the initial point. Next, the same patient was placed once again and other acquisitions were taken. This method was used in ten patients, three acquisitions each. It should be underlined that this test did not affect with any additional ion radiation threat and did not require additional radiopharmaceutical injection. The registered scintigrams of the same patients were analyzed with RAPUL program. The obtained results were statistically analyzed. The obtained differences were not statistically significant for $p<0.005$. Another stage of testing was the assessment of the program's repeatability. One examination was developed 10 times and the obtained results were compared. In this way we developed 10 different examinations. The obtained differences were not statistically significant for $p<0.005$. The obtained test results confirm the proper algorithm of the developed program. The index of upper limb muscle perfusion is a positive abstract number. In the developed method the quality of perfusion is adversely proportional to the index values. This means that lowering the absolute value of the index is synonymous with the improvement of perfusion in the muscles of upper limbs.

The examinations for this research were accepted by the Commission of Bioethics of Medical University, Lodz no. RNN/398/KB on 21.05 .2013 
Table 1. The results of basic examinations

\begin{tabular}{lcccc} 
& Age (years) & Weight $[\mathrm{kg}]$ & Height $[\mathrm{m}]$ & BMI $\left[\mathrm{kg} / \mathrm{m}^{2}\right]$ \\
\hline Mean & 30.4 & 74.75 & 1.74 & 23.53 \\
Median & 30.0 & 70.50 & 1.77 & 23.95 \\
SD & 7.1 & 11.93 & 0.09 & 2.68 \\
Min. & 20.0 & 50.00 & 1.56 & 18.82 \\
Max. & 45.0 & 105.00 & 1.89 & 27.73
\end{tabular}

\section{Results and discussion}

In the hitherto conducted examinations we analyzed the results of 20 patients qualified to the group. In these patients, we eliminated the diseases that may impair the perfusion in the area of upper limbs with the medical history, subject examination, laboratory and USG examinations. The results of anthropometric examinations are presented in Table 1.

According to the qualifying assumptions, the results (blood morphology, ionogram, glucose, lipid profile, thyroid hormones FT4 and TSH) were within the range of normal values.

Doppler USG examinations of the vessels of upper limbs performed at subclavian, radial, and brachial arteries in both arms didn't show any abnormalities. The results of FMD examination performed in brachial arteries were within 7-10\% and did not show any deviations from the normal values.

The results of examinations quantitatively assessing the perfusion in the muscles of upper limbs after the application of ${ }^{99 \mathrm{~m} T \mathrm{TC}-\mathrm{MIBI}}$ are presented in Figure 2.

The values of perfusion indexes (PI) of right and left arm had a normal distribution. The range of the left arm was within $7.20<\mathrm{PI}_{\text {_eft }}<11.90$ and of the right arm, $7.00<\mathrm{PI}_{\text {_right }}<12.30$. The correlation of dependency PI_left $v s . \mathrm{Pl}_{\text {-right }}$ was strong, $r=0.92036$. Analysis was performed with $95 \% \mathrm{Cl}$.
The values of perfusion symmetry index (IPS) had a normal distribution and were within $0.9231<$ IPS $<1.1019$. We did not observe any extreme or deviated values. The strong statistical correlation between the values of both arms proved a great symmetry of perfusion which is presented in Figure 3.

The impairment of perfusion in the muscles of upper limbs is often for a long time symptomless which makes it hard to be recognized both by the patient and the doctor. Up to now the impairment of the perfusion in muscles of upper limbs has been assessed with standard vascular examinations and the research techniques involved a qualitative assessment of perfusion changes. For many years we have been conducted the researches that allow for the assessment of muscle perfusion. This made us try to broaden this method to the possibility of quantitatively assessment of perfusion in muscles of upper limbs. The application of the new method creates the possibility of early diagnostics even in the discrete disturbances in muscles of upper limbs and the obtained results will significantly broaden the knowledge of the assessment of muscle perfusion. The accurate quantitatively recognition of blood flow in muscles of upper limbs is very useful for the proper perfusion assessment both in the healthy and medical conditions.

Some diseases impair the perfusion mainly in the area of upper limbs and this is an issue which is poorly developed. Sometimes it is very difficult to define the cause of disturbances of perfusion in muscles of upper limbs, however, its definition allows for effective treatment. For example, as we informed at the beginning of our work, in Raynaud's disease there are many primary and secondary causes. The sympathectomy is still performed as a therapeutic method, especially where there are no possibilities of procedure that would restore the normal blood flow and the ischemia diseases are prevailing. The developed radioisotope method of perfusion assessment is a sensitive test for early detection of disturbances in the perfusion of muscles in upper limbs. The applied own method and program (RAPUL) may significantly broaden our knowledge
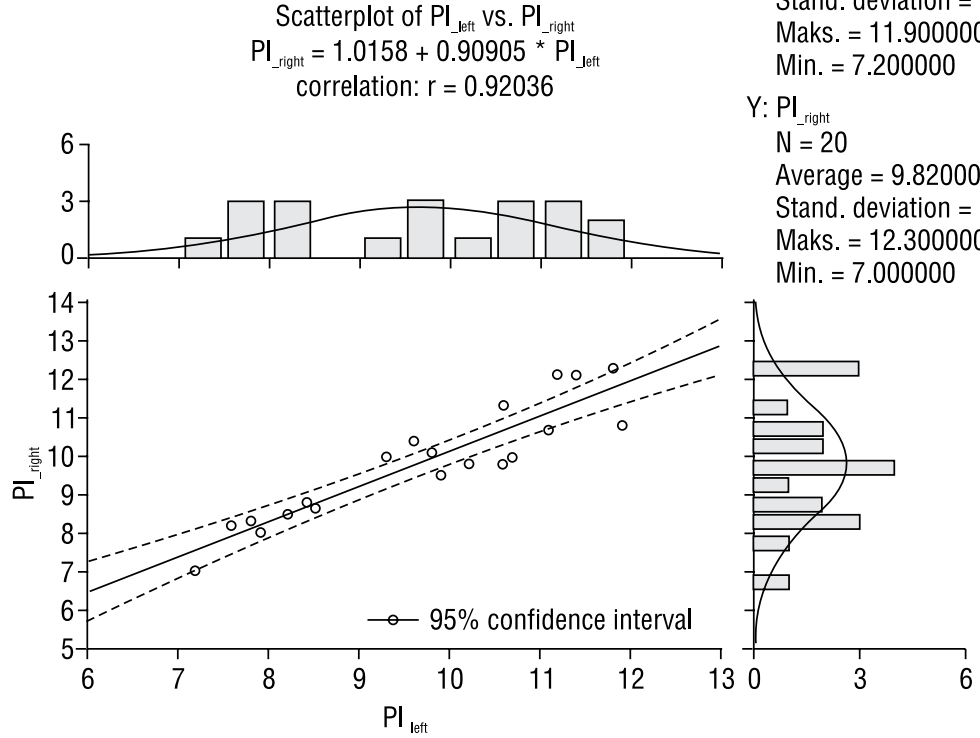

$X: \mathrm{PI}_{\text {left }}$

$\mathrm{N}=20$

Average $=9.68500$

Stand. deviation $=1.4925$

Maks. $=11.900000$

Min. $=7.200000$

$\mathrm{Y}: \mathrm{PI}_{\text {right }}$

$\mathrm{N}=20$

Average $=9.82000$

Stand. deviation $=1.4741$

Maks. $=12.300000$

Min. $=7.000000$

Figure 2. The values of the perfusion index of the right and left arm 


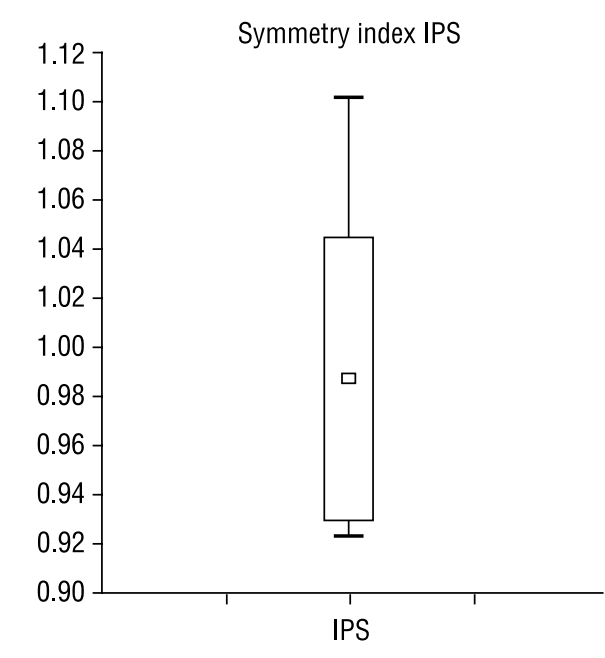

口 Average $=0.9871 \quad \square$ Average \pm STD $=(0.9293-1.0448)$

I Min.-Maks. = $(0.9231-1.1019)$

Figure 3. The index of perfusion symmetry IPS

due to the quantitatively assessment of perfusion in muscles of upper limbs and bring diagnostic and therapeutic benefits than would be used in clinics. Due to its sensitiveness and specificity, the method will allow for resignation from other hardly accessible and expensive diagnostic examinations. The discussed method may highly contribute to prognostic conclusions in the early stages of diseases and completing the diagnosis and treatment. The designated in our examinations quantitatively values of normal perfusion

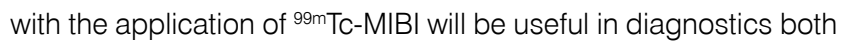
for the healthy (sports medicine, military services) and medical conditions that impair the perfusion in muscles of upper limbs. Hitherto results and their assessment allow for making more precise conclusions. Our own method and RAPUL program allow for quantitative assessment of perfusion in muscle of upper limbs. The developed program has a high repeatability of results. Our new, hitherto not used, radioisotope method, allowing for quantitative perfusion assessment, can highly broaden our knowledge by the possibilities of clinical application of quantitative diagnostics of perfusion. The presented program is an initial report concerning the method and program of quantitative perfusion assessment in the muscles of upper limbs. The results obtained in more numerous groups of healthy patients will allow for defining the range of normal values of perfusion index in upper limbs at rest and the final verification of the method which we developed.

\section{References}

1. Ashleigh RJ, Hufton AP, Razzaq R, MacDiarmaid-Gordon L. A comparison of bolus chasing and static digital subtraction arteriography in peripheral vascular disease. Br J Radiol 2000; 73: 819-824.
2. Bajnok L, Kozlovszky B, Varga J, Antalffy J, Olvaszto S, Fulop. Technetium-99m sestamibi scintigraphy for the assessment of lower extremity ischaemia in peripheral arterial disease. Eur J Nucl Med 1994; 21: 1326-1332.

3. Beckman JA, Creager MA, Libby P. Diabetes and atherosclerosis - epidemiology, pathophysiology, and management. JAMA 2002; 287: 2570-2581.

4. Celen YZ, Zincirkeser S, Akdemir I, Yilmaz M. Investigation of perfusion reserve using $99 \mathrm{Tc}(\mathrm{m})-\mathrm{MIBI}$ in the lower limbs of diabetic patients. Nucl Med Commun 2000; 21: 817-822.

5. Beręsewicz A, Lewartowski B, Opolski G (ed.) Niewydolny śródbłonek naczyniowy. Kardiologia Polska 2002; 57, supl IV.

6. Taylor PR, McColl I. Problemy ekonomiczne chorób naczyń. Chirurgia Współczesna 1993; 6: 319.

7. Małek $\mathrm{G}$ et al. Ultrasonografia Dopplerowska zastosowanie kliniczne. T. II. Warszawa 2003

8. Miles KA, Barber RW, Wraight EP et al. Leg muscle scintigraphy with 99mTc $\mathrm{MIBI}$ in the assessment of peripheral vascular (arterial) disease. Nucl Med Comm 1992; 13: 593.

9. Michallek F, Dewey M. Fractal analysis in radiological and nuclear medicine perfusion imaging: a systematic review. Eur Radiol 2013, Aug 23.

10. Segall GM, Lang GE, Lennon SE et al. Functional imaging of peripheral vascular disease: a comparison between exercise whole body Thalium perfusion imaging and contrast angiography. J Nucl Med 1992; 33: 1797-1800.

11. Małkowski $B$, Zajàc $A$, Maziarz $Z$ et al. Scintygraphic assessment of the normal value of the lower limbs' perfusion at stress and at rest with a possibility of using them in clinical practice. Pol Przegl Radiol 2005; 70: 18-24.

12. Tryniszewski W, Gadzicki M, Maziarz Z . The assessment of the range of normal values of lower limb perfusion indicators at rest and stress with the own radio isotopic method and program. Clinical and Experimental Medical Letters, vol. 48, 2008; 49: 107-113.

13. Ashleigh RJ, Hufton AP, Razzaq R, MacDiarmaid-Gordon L. A comparison of bolus chasing and static digital subtraction arteriography in peripheral vascular disease. Br J Radiol 2000; 73: 819-824.

14. Bajnok L, Kozlovszky B, Varga J, Antalffy J, Olvaszto S, Fulop. Technetium-99m sestamibi scintigraphy for the assessment of lower extremity ischaemia in peripheral arterial disease. Eur J Nucl Med 1994; 21: 1326-1332.

15. Weitz Jl, Byrne J, Clagett GP, Farkouh ME et al. Diagnosis and Treatment of Chronic Arterial Insufficiency of the Lower Extremities: A Critical Review. Elsevier Science Publishing Co 1987: 161-174

16. Małek $\mathrm{G}$ et al. Ultrasonografia Dopplerowska, zastosowanie kliniczne. T. II. Warszawa 2003

17. Conerota AJ et al. Air pletysmography: a clinical review. Ind Angiol 1995; 14: 9 .

18. Lee JW, Jeong WS, Lee SM, Kim J. Comparison of the diagnostic performances of two protocols of hand perfusion scintigraphy for Raynaud's phenomenon. Nucl Med Commun 2012; 33: 1032-1038.

19. Jager KA, Phillips DJ, Martin RL et al. Noninvasive mapping of lower limb arterial lesions. Ultrasound Med Biol 1985; 11: 515-521.

20. Królicki L Radioizotopowa diagnostyka chorób naczyń. In: Chirurgia tętnic i żył obwodowych. Noszczyk W (ed.). Wydawnictwo Lekarskie PZWL, Warszawa 1998: 162-173.

21. Lindbom A. Arteriosclerosis and arterial thrombosis in the lower limb: a roentgenological study. Acta Radiol Scand 1950; 80 (suppl): 38-48.

22. Rofsky NM, Adelman MA. MR angiography in the evaluation of atherosclerotic peripheral vascular disease. Radiology 2000; 214: 325-338.

23. Segall GM. Use of technetium-99m-MIBI in peripheral vascular disease. J Nucl Med 1992; 33: 629. 